\title{
CARBONATAÇÃO EM CONCRETO DE ESCÓRIA DE ACIARIA
}

ANDRADE, HUMBERTO

Doutorando em Engenharia Civil

Universidade Federal de Ouro Preto

Minas Gerais; Brasil

Andrade.hdias@gmail.com

\section{MATIAS, ANA CAROLINA}

Mestranda em Engenharia Civil

Universidade Federal de Ouro Preto

Minas Gerais; Brasil

ana.carolina.p.matias@gmail.com

\section{CARVALHO, JOSÉ MARIA}

Engenheiro Civil, D. Sc.

Universidade Federal de Viçosa

Minas Gerais; Brasil

jmfcarvalhoii@gmail.com
FIGUEIREDO, ALINE

Mestranda em Engenharia Civil

Universidade Federal de Ouro Preto

Minas Gerais; Brasil

alinesantanafigueiredo@gmail.com

\section{NATALLI, JULIANA}

Doutoranda em Engenharia Civil

Universidade Federal de Ouro Preto

Minas Gerais; Brasil

juliananatalli24@gmail.com

\section{PEIXOTO, RICARDO ANDRÉ}

Engenheiro Civil, D. Sc.

Universidade Federal de Ouro Preto

Minas Gerais; Brasil

fiorotti.ricardo@gmail.com

\section{RESUMO}

A utilização de materiais alternativos na produção de matrizes cimentícias se tornou uma necessidade, visto que, por um lado, há uma grande demanda do setor de construção por materiais naturais, e por outro, a necessidade de se promover destinação adequada de uma gama de resíduos industriais, cuja geração é crescente. No entanto, as matrizes alternativas devem apresentar desempenho similar às convencionais. Na presente pesquisa, concretos foram produzidos com substituição total dos agregados convencionais por agregados de escória de aciaria onde o desempenho mecânico e de durabilidade desses produtos foram verificados. A carbonatação do concreto exposto a atmosferas naturais, é um processo lento, mas os resultados para décadas de utilização precisam ser estimados em tempo viável e com boa confiabilidade. Dessa forma, testes acelerados utilizando atmosferas com alta concentração de $\mathrm{CO}_{2}$ vêm sendo propostos. Este trabalho vem contribuir para o entendimento da carbonatação de concretos produzidos com $100 \%$ de substituição de escória de aciaria, por meio da realização de ensaios acelerados. Adicionalmente, a velocidade de pulso ultrassônico e a resistência mecânica desses concretos foram avaliadas, e a relação desses parâmetros com o grau de carbonatação inferida.

Palavras-chave: carbonatação, concreto de escória, escória de aciaria.

\section{ABSTRACT}

The use of alternative materials in the production of cementitious matrices has become a necessity as, on the one hand, there is a great demand from the construction sector for natural materials, and on the other, the need to promote the proper disposal of a range of residues. whose generation is growing. However, alternative matrices should perform similarly to conventional ones. In the present research, concretes were produced with total replacement of conventional aggregates with steel slag aggregates where the mechanical performance and durability of these products were verified. Carbonation of concrete exposed to natural atmospheres is a slow process, but the results for decades of use need to be estimated in a feasible time and with good reliability. Thus, accelerated tests using atmospheres with high $\mathrm{CO} 2$ concentrations have been proposed. This work contributes to the understanding of the carbonation of concretes produced with $100 \%$ steelmaking slag substitution, by performing accelerated tests. Additionally, the ultrasonic pulse velocity and mechanical strength of these concretes were evaluated, and the relationship of these parameters with the degree of carbonation inferred.

Keywords: carbonation, slag concrete, steel slag. 


\section{INTRODUÇÃO}

A redução da geração de resíduos sólidos é meta comum para as indústrias. Dentro deste contexto, o estudo da possibilidade do aproveitamento de resíduos nos diversos segmentos da construção civil é de grande importância. O Brasil é o $9^{\circ}$ produtor de aço bruto a nível mundial, totalizando em 2017 uma produção de 31,3 milhões de toneladas de aço produzido (IAB, 2018).

As escórias de aciaria gerada a partir da produção do aço, são oriundas de dois processos; fornos conversores Linz Donawitz (BOFS), ou de Arco Elétrico (EAF). Segundo IAB (2015) a geração de resíduos em toda a cadeia produtiva do aço, gera $600 \mathrm{~kg} / \mathrm{ton}$ de aço. Considera-se que, para cada tonelada de aço produzidos são gerados $150 \mathrm{~kg}$ de escória de aciaria (IAB, 2018).

Muitos estudos de viabilidade na utilização de escórias de aço em compósitos à base de cimento foram realizados e os resultados indicam que processos como estabilização e separação magnética são eficientes na neutralização de agentes deletérios (Diniz, et al., 2017). Materiais tecnicamente competentes foram produzidos e relatados na literatura, destacando o uso de escórias de aciaria na substituição total ou parcial de agregados naturais em compósitos à base de cimento, incluindo concreto estrutural (Jesus, et al., 2011; Diniz, et al., 2017; Haltiery, et al., 2014; Barros, et al., 2014; Hernandez, et al., 2015; Hidayah Roslan, et al., 2016; Tripathi \& Chaudhary, 2016; França, et al., 2013). A viabilidade econômica do processamento e uso de escória de aciaria como agregados para construção civil e pesada também foi demonstrada (Gonçalves, et al., 2016).

A durabilidade das estruturas de concreto armado está relacionada com a integridade das armaduras frente aos ataques dos agentes agressivos do meio. A corrosão do aço, como efeito da despassivação da armadura induzida pela carbonatação do concreto é um fator preocupante. (Zhang, et al., 2013). A durabilidade do concreto está intimamente relacionada com sua porosidade, de maneira geral, concretos menos porosos são mais duráveis (Mehta \& Monteiro, 2014).

A carbonatação se expressa de forma mais efetiva em ambientes urbanos ou industriais, onde verifica-se maior exposição do concreto a níveis mais elevados de $\mathrm{CO}_{2}$. O dióxido de carbono penetra pelos poros do concreto e reage com a água disponível na estrutura, formando-se o ácido carbônico $\left(\mathrm{H}_{2} \mathrm{CO}_{3}\right)$. O ácido carbônico reage com a pasta de cimento hidratada, particularmente com o hidróxido de cálcio $\left(\mathrm{Ca}(\mathrm{OH})_{2}\right)$, e resulta em água e carbonato de cálcio $\left(\mathrm{CaCO}_{3}\right)$. Em um taxa mais baixa, há também reação com CSH (Hills, et al., 2015) (Tokudome, 2009).

O concreto possui comumente o $\mathrm{pH}$ entre 12,6 e 13,5, mas, em função do processo de carbonatação, esses valores se reduzem para uma faixa de $\mathrm{pH} 8,5$. A carbonatação ocorre da superfície externa da estrutura para o interior da mesma, segundo uma frente de carbonatação (Cascudo, 2011; Mehta \& Monteiro, 2014; Petrucci, 1998; Leemann, et al., 2015). A partir da despassivação das armaduras, os danos causados são vários, como fissuração do concreto, destacamento do cobrimento do aço, redução da seção da armadura e perda de aderência desta com o concreto (Tokudome, 2009; Ekolu, 2016).

A carbonatação é ainda função de fatores como condições ambientais (altas concentrações de $\mathrm{CO}_{2}$ ), dosagem do concreto (altas relação de água / cimento resultam em concretos porosos e, portanto, aumentam as chances de difusão de $\mathrm{CO}_{2}$ nos poros), lançamento e adensamento (se o concreto tiver baixa permeabilidade (compacto), dificultará a entrada de agentes agressivos) e cura (o concreto mal curado possui microfissuras que o enfraquecem).

Alguns estudos de carbonatação para concretos com adição de escória vem sendo desenvolvidos, porém comportamentos equivalentes aos de concretos convencionais vem sendo reportados (Tripathi \& Chaudhary, 2016). No entanto, a maioria dos estudos tratam de concretos com substituição parcial de agregados naturais por agregados de escória de aciaria, no que se difere desse estudo, que tem como objetivo, o estudo da carbonatação em concretos produzidos integralmente com agregados de escória de aciaria LD e EAF, considerando a vida útil de projeto determinada pela NBR $15575 / 2013$. 


\section{MATERIAIS E MÉTODOS}

\subsection{MATERIAIS}

Para os modelos experimentais propostos, utilizou-se cimento Portland CP V - ARI RS, por possuir alta resistência inicial, o que o faz ter um desempenho superior aos cimentos comuns para as primeiras idades. Além disso, possui maior durabilidade e resistência a sulfatos em ambientes agressivos, além de apresentar o tempo de pega igual ao CP II E40. A caracterização do cimento utilizado é mostrada na Tabela 1.

Tabela 1: Caracterização do cimento.

\begin{tabular}{cc}
\hline Ensaio & Valor \\
\hline Resíduo Insolúvel & $1,00 \%$ \\
Perda ao fogo & $3,93 \%$ \\
Índice de finura & $0,10 \%$ \\
Resíduo na peneira \#325 & $1,00 \%$ \\
Água de consistência normal & $29,50 \%$ \\
Expansibilidade à quente & $0,00 \mathrm{~mm}$ \\
Área Específica (Blaine) & $4,64 \mathrm{~cm}^{2} / \mathrm{g}$ \\
Massa Específica & $3,01 \mathrm{~g} / \mathrm{cm}^{3}$ \\
Tempos de pega & $(167-226) \mathrm{min}$ \\
Resistência a compressão (1,3,7 e 28) & $(24,1-37,5-46,3-55,2) \mathrm{MPa}$ \\
\hline
\end{tabular}

Fonte: Os autores.

Para produção dos agregados graúdo e miúdo, foi utilizado escória de aciaria oriundas do processo BOFS e EAF, ambas com aproximadamente 36 meses de intemperização. O material recebido passou pelo processo de separação magnética utilizando rolo (HF CC, Inbrás®), para retirada da fração magnética, e submetido ao processo de separação gravimétrica, afim de obter a curva granulométrica de Brita Zero $(4,75$ - 12,5) mm, estipulada pela NBR 7211 (ABNT, 2009) conforme Figura 1.

Figura 1: Distribuição Granulométrica dos agregados.

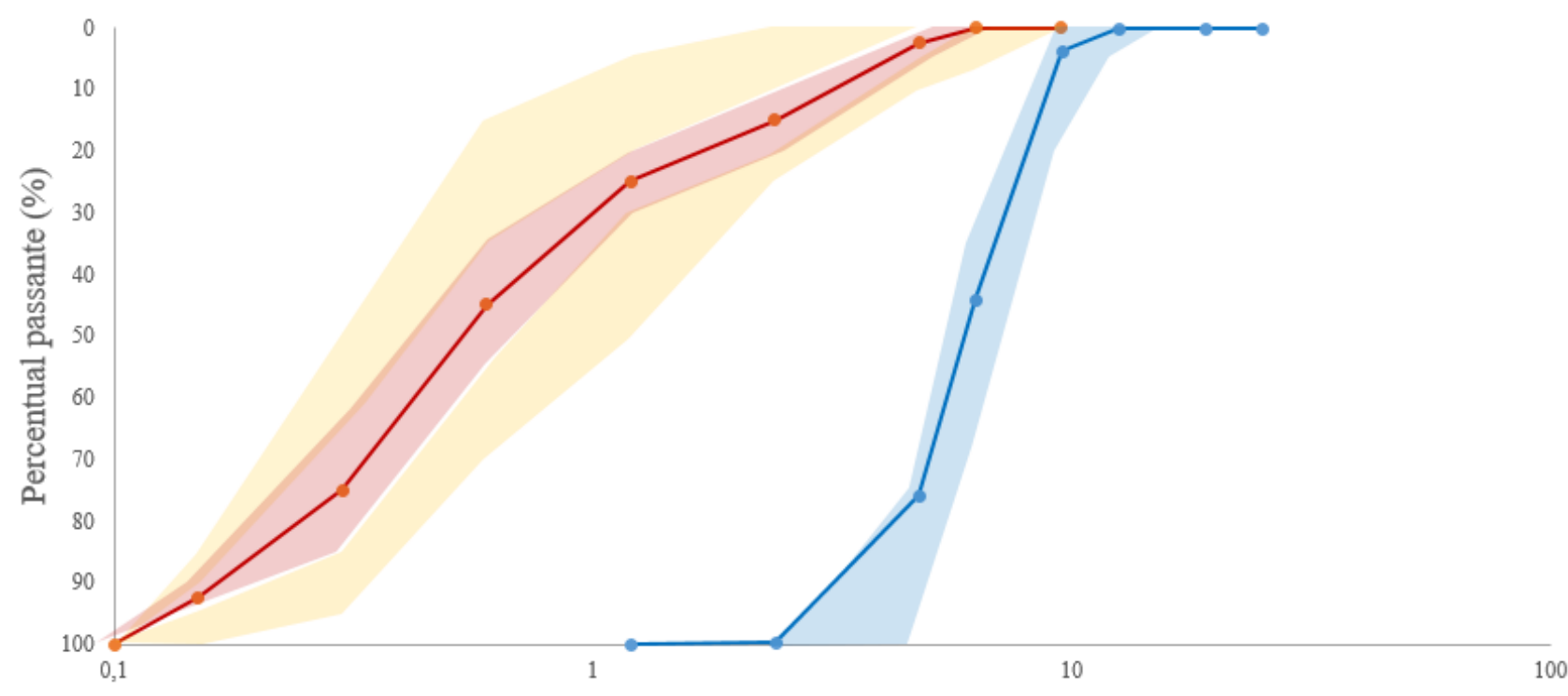

Abertura da malha (mm)

-•Agregado graúdo $\bullet$ Agregado Miúdo

Fonte: Os autores. 
Os agregados miúdos utilizados para produção das matrizes resultam do processo de cominuição das escórias em britador de mandíbulas (BB 200, Retsch®), afim de se obter um material com granulometria inferior 4,8 mm. A seguir, o material também foi submetido a processo de separação magnética. Finalmente o material passou pelo processo de segregação gravimétrica por peneiramento, adequando com limites indicados pela NBR 7211 (ABNT, 2009), conforme Figura 1.

Quanto aos resultados de massa específica dos agregados miúdos, os resultados para BOF, EAF e AR foram 3,52; 3,76 e $2,6 \mathrm{~g} / \mathrm{cm}^{3}$, respectivamente. Na mesma sequência para os agregados graúdos foram 3,32;3,48 e 2,61 g/cm ${ }^{3}$. A diferença nos valores de massa específica, é justificada pela composição química dos materiais, onde, a escória apesentam cerca de $30 \%$ de ferro. Ainda se percebe que a escória EAF possui 4,5\% a mais de FeO do que a BOF. A diferença entre os valores de massa específica é de mesma ordem.

A relação água/cimento foi fixada segundo a classe de resistência, sendo de 0,$64 ; 0,48 ; 0,44$ para matrizes $C_{15}, C_{25}$ e $C_{35}$, respectivamente. Os teores de água e cimento foram adotadas, afim de que se produzissem matrizes com características reológicas semelhantes, relativamente a consistência e trabalhabilidade, controladas pelo abatimento das matrizes (SLUMP test - NBR NM 67 (ABNT, 1998)) definido em 80mm $( \pm 10 \mathrm{~mm})$. As estratégias propostas para produção de matrizes com a mesma trabalhabilidade buscaram produzir resultados em que se identificassem as propriedades dos materiais.

Para cada mistura, foram produzidas matrizes sem aditivos (REF / EAF / BOFS) e com aditivo (REF - A / EAF - A / BOFS - A). A dosagem de aditivos foi determinada de acordo com um método baseado no proposto por Aitcin (2000), que determina o ponto de saturação da mistura de superplastificante (Aitcin, 2000; Damineli, et al., 2010) e o aditivo utilizado foi MC - POWERFLOW 1180 (MC - Bauchemie®).

A análise química das escórias utilizados foi realizada por difração de raio-x (DRX), conforme Figura 2 e Figura 3. Para a realização do ensaio utilizou-se as configurações: Cuk $\alpha$ (2.54184 Angstron) radiation; tube setting $30 \mathrm{kV}$ and $10 \mathrm{~mA}$, a step size of $0.018^{\circ}$; step time of $1 \mathrm{~s}$ and 2 teta range of $7^{\circ}$ to $70^{\circ}$. Em ambos materiais percebe-se valores mais altos de Periclase, Brownmillerite, Akermanite, Calcite and Westite. Todos esses compostos e os demais apontados pela DRX, estão em comum acordo com a literatura.

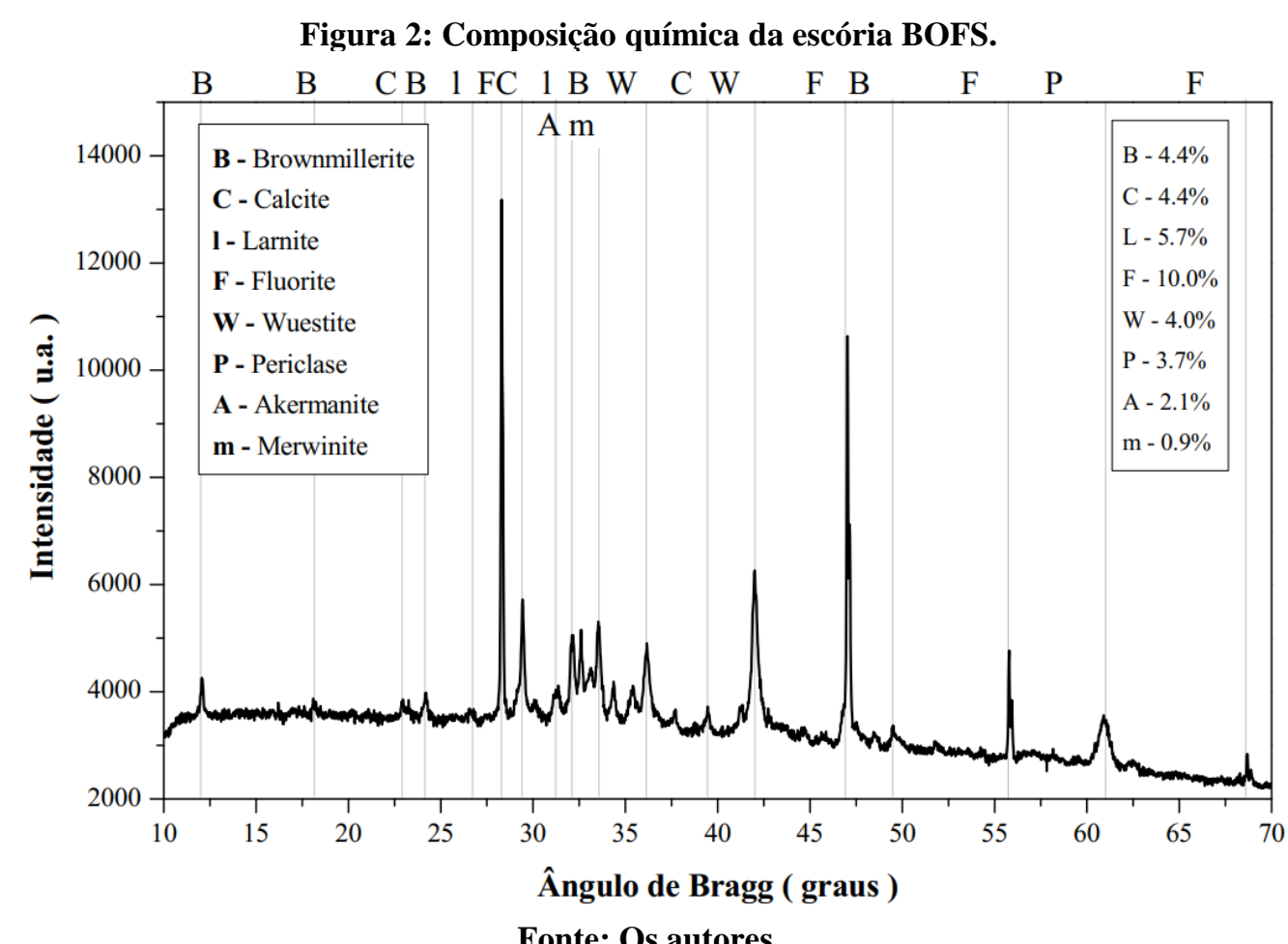

Fonte: Os autores. 
Figura 3: Composição química da escória EAF.

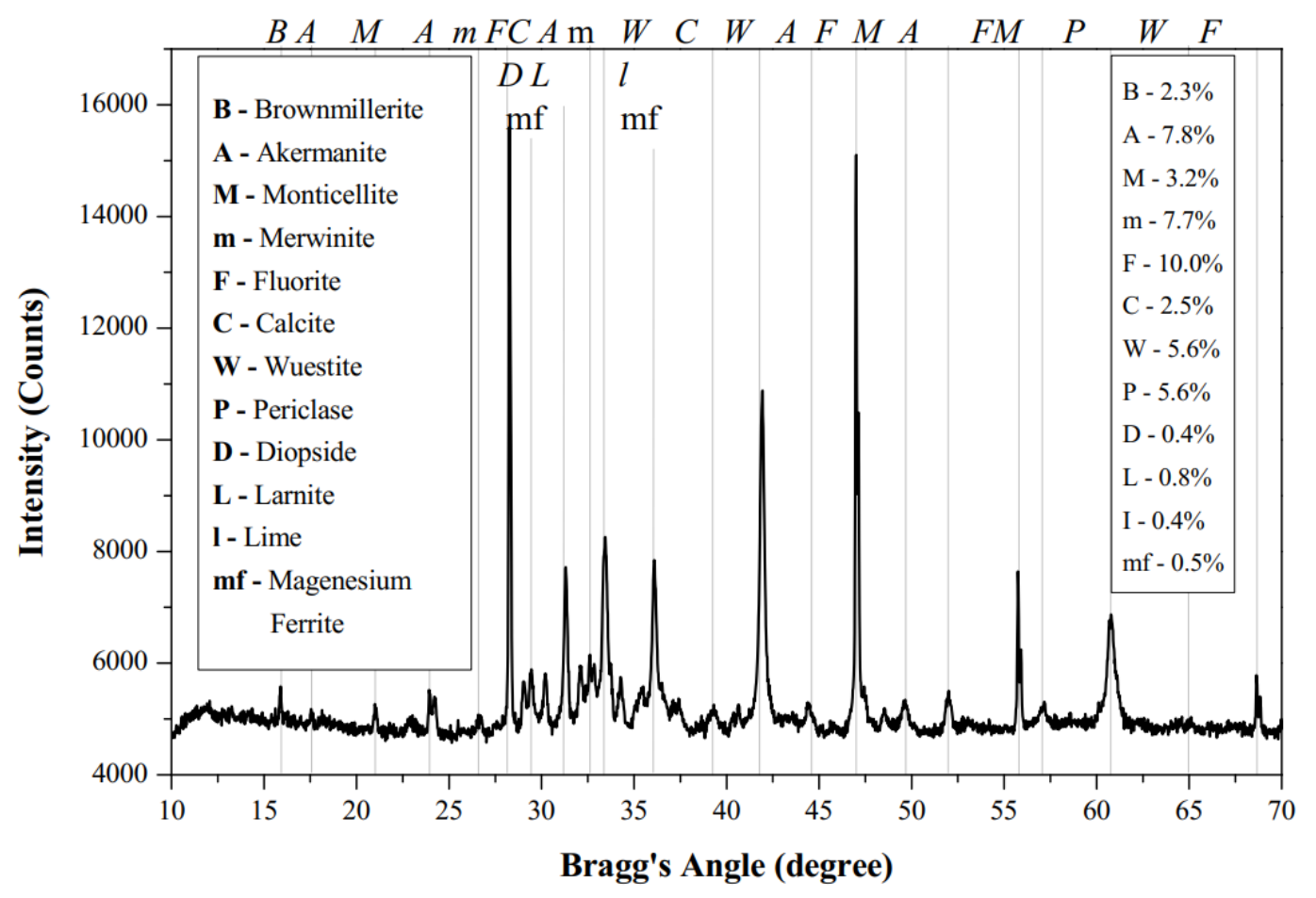

Fonte: Os autores.

\subsection{MÉTODOS}

As misturas foram projetadas de acordo como método ABCP em Software Especialista para Dosagens de Misturas Cimentícias, Soares (2009). O método escolhido, se justifica pelo fato de considerar todas as características dos agregados. Foi considerado 1 classe de resistência à compressão aos 28 dias de idade, sendo ela: $\mathrm{C}_{15}(15 \mathrm{MPa})$. A consistência foi determinada pelo abatimento de tronco de cone conforme NBR NM 67 (ABNT, 1998), e fixada em $80 \pm 10 \mathrm{~mm}$ para todos os traços mostrados na Tabela 2.

Tabela 2: Traços utilizados.

\begin{tabular}{ccccc}
\hline Material & Cimento & Areia & Brita & Água \\
\hline EAF15 & 1 & 2,6 & 3,5 & 0,64 \\
\hline BOF15 & 1 & 2,63 & 3,45 & 0,64 \\
\hline REF15 & 1 & 1,69 & 2,55 & 0,64 \\
\hline
\end{tabular}

Fonte: Os autores.

Para análise da resistência a compressão, índice de vazios, absorção de água, massa específica, velocidade de pulso ultrassônico e carbonatação, também foram produzidas matrizes cimentícias com aditivo superplastificante. Os corpos de prova (CP) foram moldados em duas camadas, adensadas em mesa de fluxo com 15 golpes por camada, e intervalo de 1 segundo entre golpes. A cura dos corpos de prova ocorreu em câmara úmida com temperatura de $23 \pm 2{ }^{\circ} \mathrm{C}$ e umidade relativa de 95\%, conforme prescrito pela NBR 9479 (ABNT, 2006).

Os corpos de prova foram submetidos a ensaios de resistência à compressão NBR 5739 (ABNT, 2007), velocidade de pulso ultrassônico NBR 8802 (ABNT, 2013), massa específica NBR 9778 (ABNT, 2005), índice de vazios NBR 9778 (ABNT, 2005) e absorção de água NBR 9778 (ABNT, 2005).

Para a determinação da durabilidade, tendo como parâmetro a norma de desempenho de habitações, NBR 15575 (ABNT, 2013), foram conduzidos ensaios de carbonatação acelerada utilizando-se a câmara de carbonatação - SCO 26H ShelLab®. Os parâmetros utilizados para os ensaios acelerados no presente trabalho, foram adaptados dos trabalhos de Sanjuán et al. (2003) e Ho \& Lewis (1987) apresentados na Tabela 3. 
Tabela 3: Parâmetros utilizados no ensaio de carbonatação acelerada.

\begin{tabular}{cc}
\hline Parâmetro & Valor \\
\hline Umidade relativa & $50-60 \%$ \\
Temperatura & $25 \pm 1{ }^{\circ} \mathrm{C}$ \\
Concentração $\left(\mathrm{CO}_{2}\right)$ & $8-10 \%$ \\
\hline
\end{tabular}

Fonte: (Sanjuán, et al., 2003); (Ho \& Lewis, 1987), adaptado.

Para a análise da carbonatação os corpos de prova foram recobertos com uma camada de fita "silver tape" (constituída de um filme de polietileno na cor prata e trama de tecido com adesivo à base de resina e borracha), ao longo do comprimento. $\mathrm{O}$ conjunto $\mathrm{CP}$ e fita foram selados externamente com camada adicional de parafina, expondo à atmosfera $\mathrm{com}_{\mathrm{CO}}$ apenas a face superior, induzindo os processos de carbonatação preferencialmente segundo a geratriz do corpo de prova, considerando o comprimento de $10 \mathrm{~cm}$ para frente de carbonatação, conforme padrão CPC - 18 (RILEM, 1988). Uma imagem esquemática do modelo de impermeabilização adotado para o corpo de prova é apresentada na Figura 4.

Figure 4: Esquema de impermeabilização do CP.

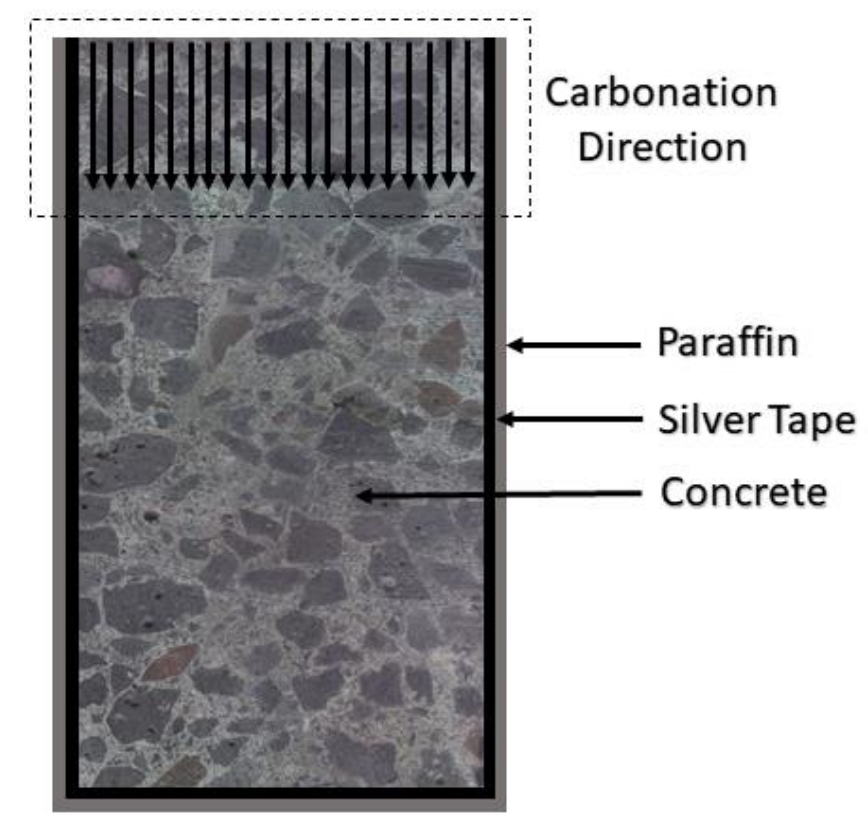

Fonte: Os autores.

Para determinação da profundidade de carbonatação, foi utilizado método colorimétrico, empregando-se solução de fenolftaleína 1\% (meio alcoólico), conforme prescrições da norma CPC-18 (RILEM, 1988). Para tal procedimento, o CP é fraturado ao longo do comprimento. Todos os ensaios foram realizados após a cura de 28 dias do concreto.

\section{RESULTADOS E DISCUSSÃO}

\subsection{CARACTERIZAÇÃO FÍSICA DO CONCRETO NO ESTADO ENDURECIDO}

Percebe-se uma redução do índice de vazios dos concretos produzidos com escória EAF de 3,77\% quando analisado junto ao concreto convencional. Os traços compostos por BOF mostram de redução de $4,8 \%$ quando comparado ao concreto de referência. Comparando os concretos entre tratamentos, percebe-se que os concretos de escória apresentaram menores porcentagens conforme mostrado na Figura 5.

Os resultados apresentados na Figura 5 mostram que os concretos produzidos com agregados de escória de aciaria EAF apresentam uma diminuição de $2,6 \%$ para absorção de água enquanto os concretos produzidos com escória BOF obtiveram uma redução de $2,2 \%$. 
Figura 5: Índice de Vazios e Absorção de Água.

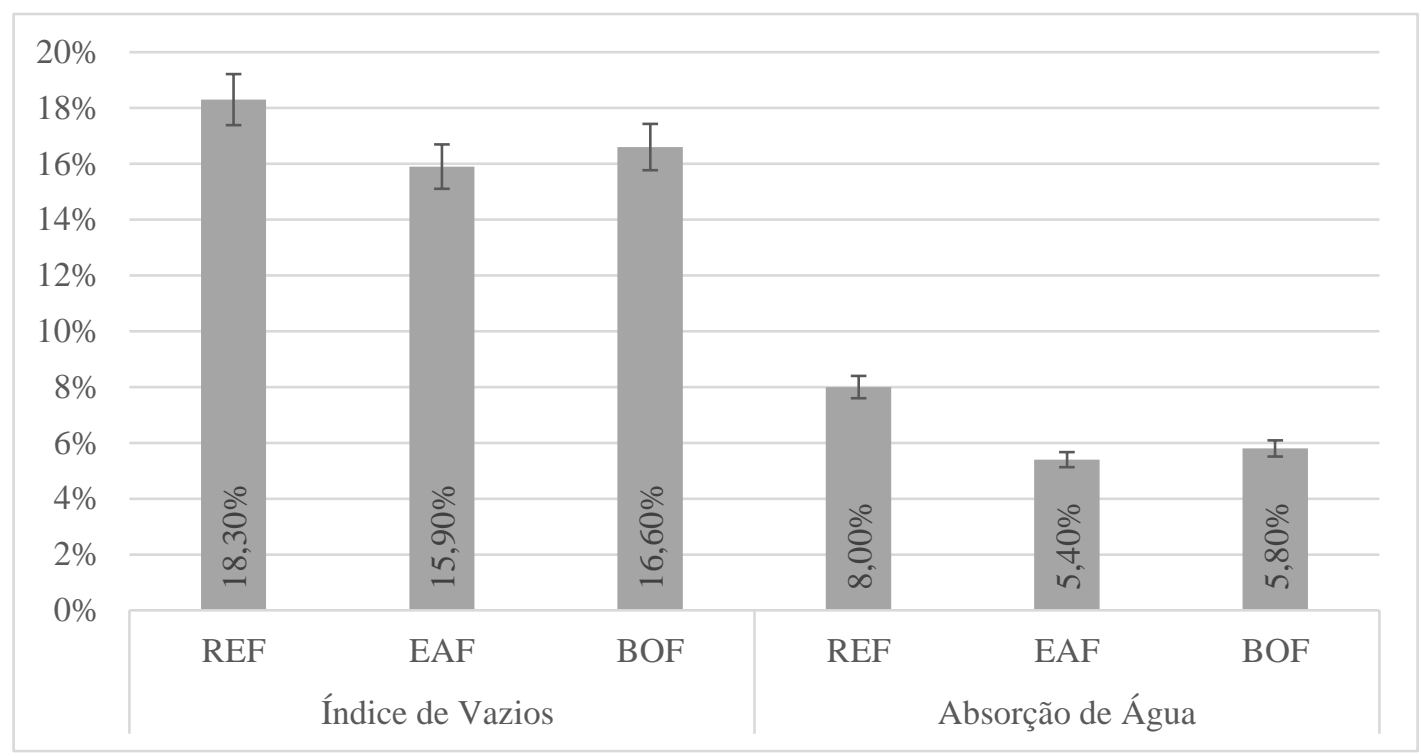

Fonte: Os autores.

Os resultados obtidos para massa especifica são apresentados na Figura 6, onde todos os concretos produzidos com escória de aciaria apresentam valores de massa específica superiores aos concretos de referência. Esses dados vão de encontro com os resultados encontrados nos ensaios de massa específica dos agregados utilizados conforme apresentados anteriormente.

Santamaría, Orbe, San José, \& González (2018), fizeram um estudo sobre a durabilidade do concreto estrutural incorporando escória de aciaria em diferentes proporções e granulometrias, e dentro de suas considerações, mostram que a massa específica dos concretos de escória aumentou de 10 a 15\% em relação aos concretos produzidos com agregados convencionais.

\section{Figura 6: Massa Específica.}

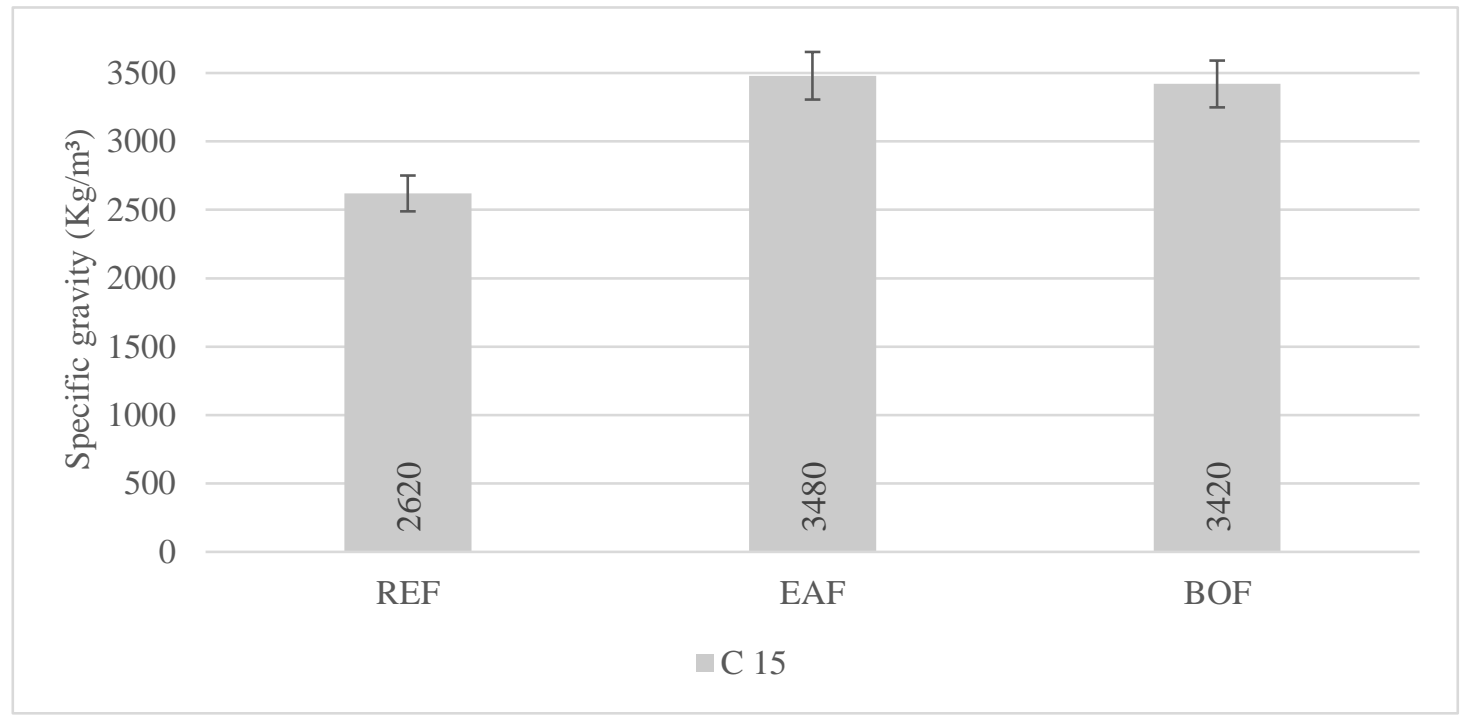

Fonte: Os autores.

Os concretos de escória são classificados como concretos pesados, e os concretos produzidos com agregados convencionais se enquadram na faixa de concretos normais (ABNT, 2015). Os valores de massa específica variando de 2000 a $2800 \mathrm{~kg} / \mathrm{m}^{3}$ caracterizam os concretos como normais, concretos leves apresentam massa específica abaixo de 2000 $\mathrm{kg} / \mathrm{m}^{3}$, e os concretos pesados apresentam massa específica maior que $2800 \mathrm{~kg} / \mathrm{m}^{3}$. (Mehta \& Monteiro, 2014; Han-Seung \& Wang, 2016; Freitas, 2012; Natalli, 2017; ABNT, 2015). 
Os resultados de resistência à compressão aos 28 dias são apresentados na Figura 7. É possível perceber através desses resultados que todos os concretos producidos com agregados de escória de aciaria apresentam resultados superiores aos concretos produzidos com agregados convencionais. Vale ressaltar que todos os concretos tiveram o mesmo abtimento (80 mm) e o mesmo fator água/cimento, atribuindo esse aumento de resistência as características dos materiais utilizados.

Os valores encontrados para os concretos de escória, estão em concordância, com os resultados anteriormente apresentados, onde, esses concretos, apresentaram menores valores de índice de vazios, menor valor de absorção de água e maior massa específica.

Figura 7: Resistência à compressão.

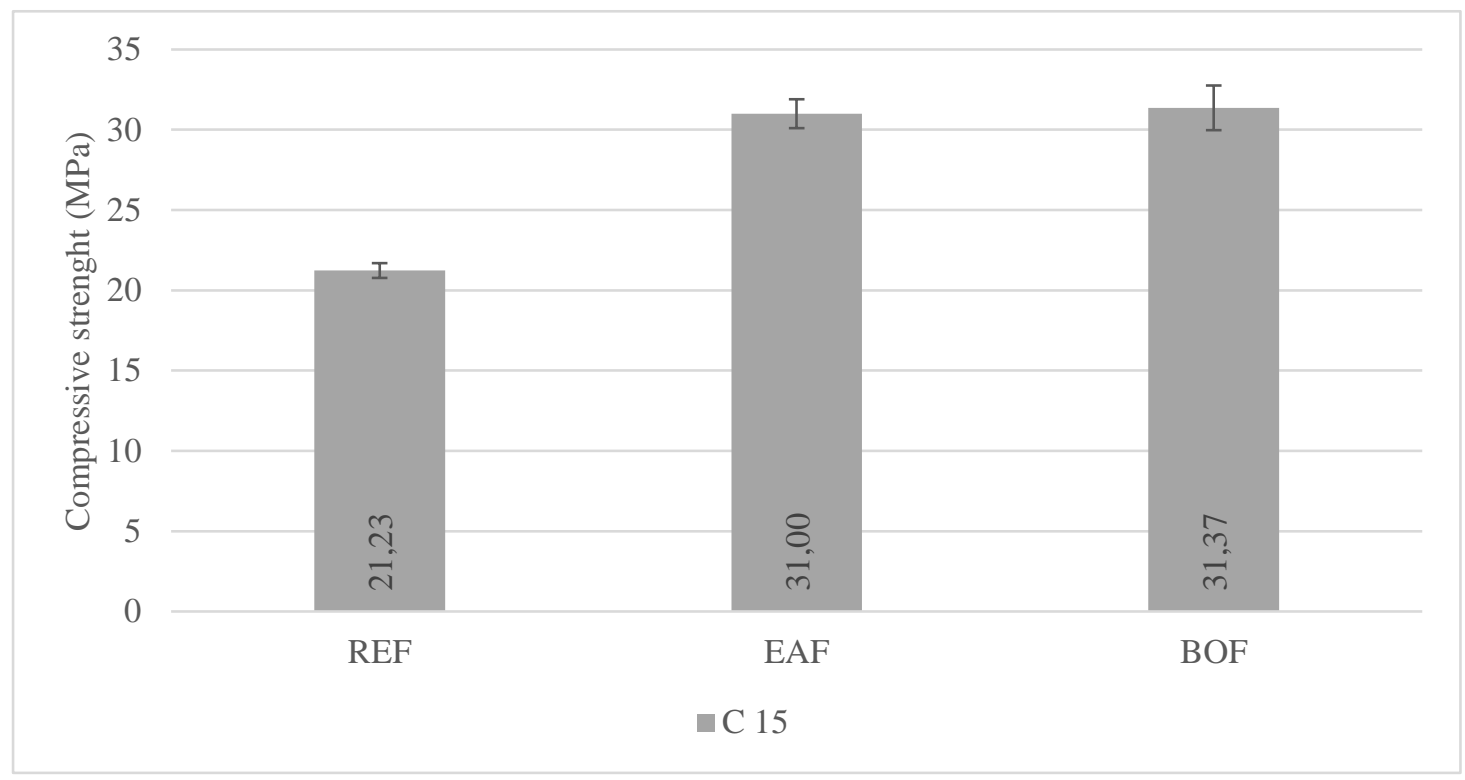

Fonte: Os autores.

Concretos produzidos com escória de aciaria apresentam resultados para resistência à compressão melhores quando comparados aos concretos produzidos com agregados convencionais (Rondi, et al., 2015) (Zhang, et al., 2011). Em seu estudo, Monosi, Ruello, \& Sani (2015) encontrou melhora de 66\% para resistência a compressão concretos com substituição de agregado natural por agregado de escória de aciaria.

O bom desempenho dos concretos de escória se deve em parte à ação cimentante do material, indicada pelo considerável teor de $\mathrm{CaO}$. No entanto, a ação cimentante esperada é mais lenta e os resultados são melhores a longo prazo (Diniz, et al., 2017). No estudo de Qiang, Peiyu, Jianwei, \& Bo (2013), foi observado o aumento de 87,5\% da resistência a compressão dos concretos com substituição parcial de $45 \%$ de escória quando se compara a resistência aos 10 dias e 100 dias. Para os de referência, o aumento foi apenas de 50\%, evidenciando a ação cimentante da escória.

Os estudos de Pang, Zhou, \& Xu, (2015) e Özbay, Erdemir, \& Ibrahim Durmus, (2016) também relatam aumento de resistência em concretos produzidos com escória na faixa de $15 \%$ a $44 \%$ a medida em que se aumenta a porcentagem de substituição do agregado convencional por escória e a idade do mesmo.

\subsection{CARBONATAÇÃO ACELERADA}

Os resultados de carbonatação obtidos para os concretos produzidos com escória de aciaria foram melhores quando comparados aos concretos fabricados com agregados convencionais, conforme mostrados na Tabela 4 e na Figura 8. Qiang, Peiyu, Jianwei, \& Bo (2013) apontam em seu estudo, que concretos com substituição parcial (até 45\%) de agregado natural por escória de aciaria, com 3 ou mais dias cura, apresentam boa resistência à carbonatação. 
Tabela 4: Carbonatação.

\begin{tabular}{cc}
\hline Concreto & Profundidade de carbonatação \\
\hline REF & $40,5 \mathrm{~mm}$ \\
\hline EAF & $12,5 \mathrm{~mm}$ \\
\hline BOF & $13,3 \mathrm{~mm}$ \\
\hline
\end{tabular}

Fonte: Os autores.

No entanto não existe um consenso na literatura quanto a eficácia de escória de aciaria na redução à carbonatação. Santamaría A. , et. all (2018) expôs corpos de prova de concreto convencional e fabricados com agregados de escória à ambientes agressivos. Ambos tiveram resultados similares quando aplicados ao indicador de fenolftaleína, não indicando vantagens ao se utilizar a escória de aciaria (Santamaría, et al., 2018).

Por outro lado, para substituição total dos agregados (conforme presente trabalho) os resultados foram favoráveis. Qiang, Peiyu, Jianwei, \& Bo (2013) mostra em seu trabalho que a profundidade de carbonatação em concretos com substituição parcial diminui à medida em que o tempo de cura aumenta, onde, a carbonatação de concretos com 28 dias de cura, apresentam resultados com $66 \%$ menos carbonatação quando comparados com concretos curados por 3 dias.

De forma geral, o bom desempenho à profundidade de carbonatação do concreto de escória EAF, vão de encontro com os resultados da caracterização física do concreto. Observa-se que, os concretos EAF apresentam menores valores de índice de vazios e menor valor para absorção de água. Todos esses parâmetros apontam que o concreto EAF é menos poroso do que BOF e REF, permitindo menor penetração do $\mathrm{CO}_{2}$.

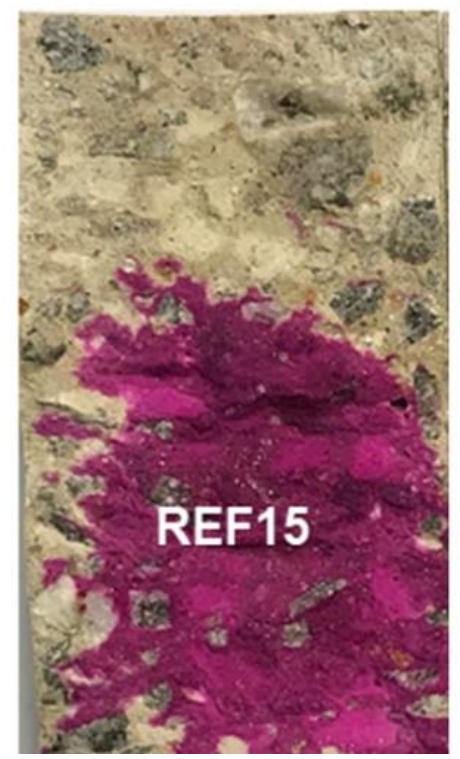

Figura 8: Carbonatação.
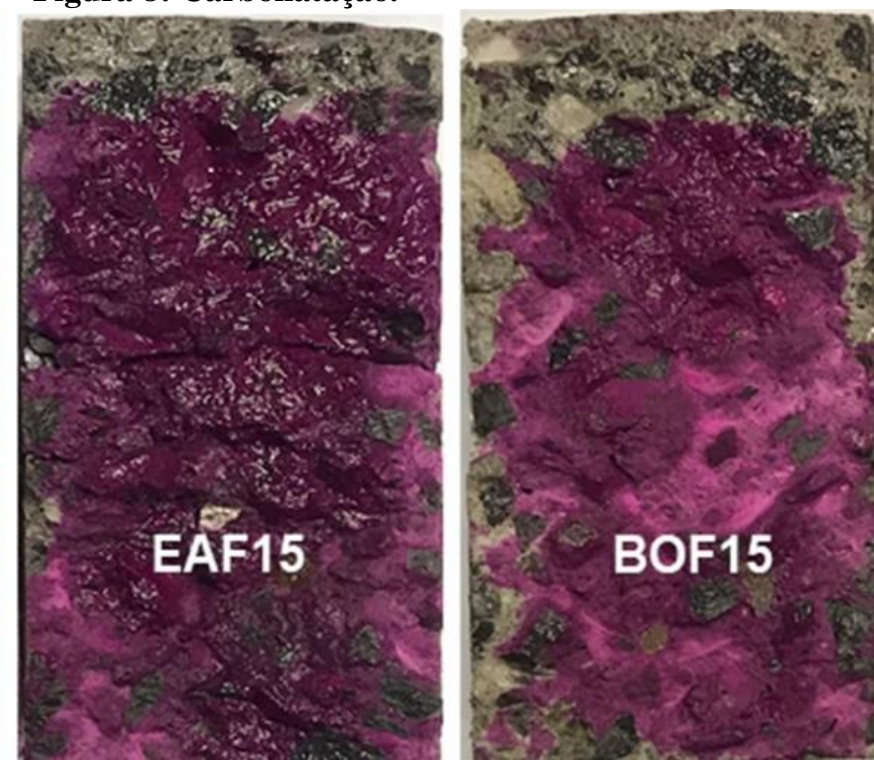

Fonte: Os autores.

\subsection{VELOCIDADE DE PULSO ULTRASSÔNICO}

Um parâmetro que está diretamente ligado com a carbonatação é a velocidade de pulso ultrassônico, visto que a onda se propaga com maior dificuldade no vazio. Na Figura 9 é correlacionado os valores de VPU e carbonatação para cada tipo de concreto produzido neste estudo.

Observa-se que quanto menor a velocidade do pulso ultrassônico, maior registro de carbonatação, sendo esse fenômeno apresentado pelos concretos de referência. Ao analisar os tratamentos de escória, percebe-se que a VPU aumenta enquanto a carbonatação diminui, o que corrobora com os resultados encontrados na caracterização física do concreto no estado endurecido. 
Figura 9: Correlação entre VPU e Carbonatação.

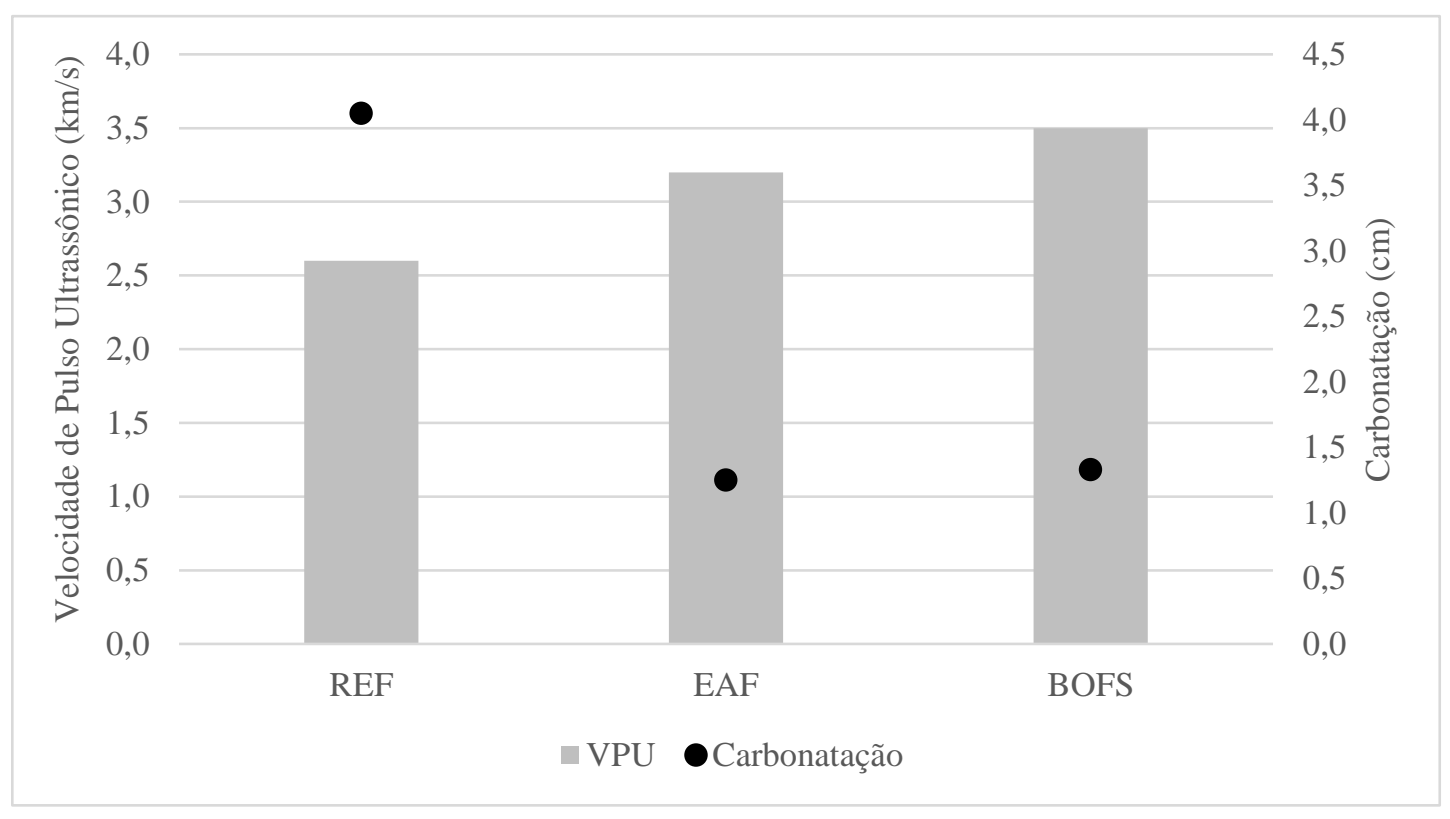

Fonte: Os autores.

\section{CONCLUSÃO}

Ao produzir concretos com $100 \%$ de substituição de agregado natural por agregados de escória, e compará-los, nota-se:

- Redução do valor de índice de vazios e absorção de água;

- Aumento da velocidade de pulso ultrassônico;

- Maiores valores de massa específica, induzido pelo maior valor de massa específica dos agregados de escória;

- Maiores resultados de resistência à compressão;

- Menor profundidade de carbonatação.

O aumento considerável na resistência à compressão dos corpos de prova produzidos com agregados de escória de EAF e BOF é condizente com os valores encontrados na caracterização física do concreto. Todos os traços de escória apresentaram melhor desempenho no teste de carbonatação acelerada mostrando que os concretos de escória apresentaram desempenho, em média, $80 \%$ melhores que os concretos convencionais.

O bom desempenho dos concretos estudados acarretam em um ganho ambiental de grande valia, haja vista a quantidade de resíduos que a produção do aço gera. Associando o bom desempenho dos concretos estudados com seus valores de massa específica, pode-se então indicar a utilização desses concretos em obras de fundação, obras de artes especiais, obras situadas em ambientes agressivos, elementos de rápida desforma, peças pré-moldadas, entre outras aplicações.

\section{AGRADECIMENTOS}

O presente trabalho foi realizado com apoio da Coordenação de Aperfeiçoamento de Pessoal de Nível Superior - Brasil (CAPES) - Código de Financiamento 001. Os autores também agradecem à FAPEMIG, CNPq e UFOP pelo apoio para a realização e apresentação dessa pesquisa. Somos gratos ainda pela infraestrutura e colaboração do Grupo de Pesquisa em Resíduos Sólidos - RECICLOS - CNPq.

\section{REFERÊNCIAS BIBLIOGRÁFICAS}

ABNT, 1998. NBR NM 67 - Concreto - Determinação da consistência pelo abatimento do tronco de cone. s.1.:s.n.

ABNT, 2005. NBR NM 23: Argamassa e concreto endurecidos - Determinação da absorção de água, índice de vazios e massa específica. s.l.:s.n.

ABNT, 2006. NBR 9479: Argamassa e concreto - Câmaras úmidas e tanques para cura de corpos-de-prova. s.1.:s.n. 
ABNT, 2007. NBR 5739: Concreto - Ensaios de compressão de corpos-de-prova cilíndricos. s.1.:s.n.

ABNT, 2009. NBR 7211: Agregados para concreto - Especificações. s.1.:s.n.

ABNT, 2013. NBR 15575: Edificações habitacionais - Desempenho. s.1.:s.n.

ABNT, 2013. NBR 8802 - Determinação da velocidade de propagação de onda ultrassônica. s.1.:s.n.

ABNT, 2015. NBR 8953: Concreto Para Fins Estruturais - Classificação pela massa específica, por grupos de resistência e consistência. Rio de Janeiro: Associação Brasileira de Normas Técnicas.

Aïtcin, P.-C., 2000. Cements of yesterday and today Concrete of tomorrow. Cement and Concrete Research, 29 Novembro, pp. 1349 - 1359.

Aitcin, P. C., 2000. Hight performance concrete. São Paulo(SP): PINI.

Barros, T. et al., 2014. Blocos de Escória de Aciaria para Alvenaria Estrutural. Em: Anais do XXII Seminário de Iniciação Científica da Universidade Federal de Ouro Preto. s.l.:UFOP, p. 1.

Bravo, M., Brito, J., Evangelista , L. \& Pacheco , J., 2017. Superplasticizer's efficiency on the mechanical properties of recycledaggregates concrete: Influence of recycled aggregates composition andincorporation ratio. Construction and Building Materials, pp. 129 - 138.

Cascudo, 2011. Action of carbonation on concrete. Em: G. C. Isaia, ed. Concrete: Science and Technology. São Paulo: IBRACON, pp. 849-886.

Damineli, B. L., Kemeid, F. M., Aguiar, P. S. \& John, V. M., 2010. Measuring the eco-efficiency of cement use. Cement \& Concrete Composites, 15 Julho, pp. 555 - 562.

Diniz, D. H., Carvalho, J. M. F., Mendes, J. C. \& Peixoto, R. A. F., 2017. Blast Oxygen Furnace Slag as Chemical. Journal of materials in civil engineering, Maio.Volume 29.

Ekolu, S. O., 2016. A review on effects of curing, sheltering, and CO2 concentration upon natural carbonation of concrete. Construction and Building Materials, Volume 127, pp. 306-320.

França, M. et al., 2013. Argamassa de Escória de Aciaria Elétrica para Assentamento de Alvenarias e Revestimento. $X$ Simpósio Brasileiro de Tecnologia das Argamassas.

Freitas, R. P., 2012. Controle de Qualidade em Concreto Endurecido: Ensaios Mecânicos. Em: Juiz de Fora - MG : Universidade Federal de Juiz de Fora, p. 55.

Gonçalves, D. R. et al., 2016. Evaluation of the economic feasibility of processing plant for steelmaking slag. Wast \& Managgement, 34(2), pp. 107-120.

Haltiery, D. et al., 2014. Blocos de concreto produzidos com escória de aciaria para uso em alvenaria modular. Em: Anais do $56^{\circ}$ Congresso Brasileiro de Concreto. Natal: IBRACON, pp. 1 - 16.

Han-Seung, L. \& Wang, X.-Y., 2016. Evaluation of compressive strength development and carbonation depth of high volume slag-blended concrete. Construction and Building Materials, Volume 124, pp. 45-54.

Hernandez, R. A. C., Cortés, C. M. P. \& Bustos, L. P., 2015. Durability and acoustics of concrete with slag of cupola furnace as fine aggregate replacement.. Tecnura, 19(43), pp. 37 -51.

Hidayah Roslan, N., Ismail, M., Abdul-Majid, Z. \& Ghoreishiamiri, S., 2016. Performance of steel slag and steel sludge in concrete. Construction and Building Materials, Volume 104, pp. 16 - 24.

Hills, T. P., Gordon, F., Florin, N. H. \& Fennel, P. S., 2015. Statistical analysis of the carbonation rate of concrete. Cement and Concrete Research, Volume 72, pp. 98-107.

Ho, D. \& Lewis, R., 1987. CARBONATION OF CONCRETE AND ITS PREDICTION. CEMENT and CONCRETE RESEARCH, pp. 489 - 504.

$\mathrm{IAB}$

2015.

Available

[Acedido em 17 Maio 2017].
Processo

at: siderúrgico. http://www.acobrasil.org.br/site2015/processo.html 
IAB, 2018. Relatório de Sustentabilidade - Instituto Aço Brasil - IAB. [Online] Available at: http://www.acobrasil.org.br/sustentabilidade/ [Accessed 17 Junho 2017].

Jesus, V. G. et al., 2011. Habitações Sustentáveis Construídas a Partir de Elementos Construtivos Produzidos com Resíduos de Escória de Aciaria. Em: Anais do $53^{\circ}$ Congresso Brasileiro de Concreto. $53^{\circ}$ ed. Florianópolis: IBRACON, pp. 1 - 10.

Leemann, A., Nygaard, P., Kaufmann, J. \& Loser, R., 2015. Relation between carbonation resistance, mix design and exposure of mortar and concrete. Cement \& Concrete Composites, Volume 62, pp. 33-43.

Mehta, P. K. \& Monteiro, P. J., 2014. Concrete: microestructure, propreties and materials. São Paulo: IBRACON.

Monosi, S., Ruello, M. L. \& Sani, D., 2015. Electric arc furnace slag as natural aggregate replacement in concrete production. Cement and Concrete Composites, 12 Agosto, pp. 66-72.

Natalli, J. F., 2017. Desempenho do Concreto Leve em Seções Mistas. Em: Ouro Preto - MG: Universidade Federal de Ouro Preto, p. 97.

Özbay, E., Erdemir, M. \& Ibrahim Durmus, H., 2016. Utilization and efficiency of ground granulated blast furnace slag on concrete properties - A review. Construction and Building Materials, Volume 105, pp. 423-434.

Pang, B., Zhou, Z. \& Xu, H., 2015. Utilization of carbonated and granulated steel slag aggregate in concrete. Construction and Building Materials, Volume 84, pp. 454-467.

Petrucci, E. G. R., 1998. Portland cement concrete. 13th ed. São Paulo: Globo.

Qiang, W., Peiyu, Y., Jianwei, Y. \& Bo, Z., 2013. Influence of steel slag on mechanical properties and durability of concrete. Construction and Building Mayerials, Volume 47, pp. 1414 - 1420.

RILEM, 1988. CPC-18: Measurement of hardened concrete carbonation depth. Materials and Structures, 21(126), pp. 453-455.

Rondi, L. et al., 2015. Concrete with EAF steel slag as aggregate: A comprehensive technical and environmental characterisation. Composites, 27 Outubro, pp. 195-202.

Sanjuán, M. A., Andrade, C. \& Cheyrezy, M., 2003. Concrete carbonation tests in natural and accelerated conditions. Advances in Cement Research, 15(4), pp. 171-180.

Santamaría, A., Orbe, A., San José, J. \& González, J., 2018. A study on the durability of structural concrete incorporating electric steelmaking slags. Construction and Building Materials, pp. 94 - 111.

Santamaría, A., Orbe, A., San José, J. \& González, J., 2018. A study on the durability of structural concrete incorporating electric steelmaking slags. Construction and Building Materials, pp. 94 - 111.

Soares, A. F. F., 2009. Specialized software for mix design of cement-based composites. Belo Horizonte: CEFET-MG.

Tokudome, $\quad 2009 . \quad$ N., Carbonatação do concreto. [Online] Available at: http://www.cimentoitambe.com.br/carbonatacao-do-concreto/

[Acedido em 22 Maio 2017].

Tripathi, B. \& Chaudhary, S., 2016. Perfomance based evaluation of ISF slag as substitute of natural sand in concrete. Cleaner Production, Volume 112, pp. 672-683.

Tripathi, B. \& Chaudhary, S., 2016. Perfomance based on evaluation of ISF slag as substitute of natural sand in concrete. Journal of Cleaner Production, Volume 112, pp. 672-683.

Zhang, T., Yu, Q., Wei, J. \& Li, J., 2011. Investigation on mechanical properties, durability and micro-structural development of steel slag blended cements. Journal Therm Calorim, 17 Agosto, pp. 633-639.

Zhang, X. et al., 2013. Studies on forescasting of carbonation depht of slag hight performance concrete considering gas permeaboloty. Applied Clay Science, Volume 79, pp. 36 - 40. 